\title{
Osteoarthritis subpopulations and implications for clinical trial design
}

Sita MA Bierma-Zeinstra* ${ }^{* 1,2}$ and Arianne P Verhagen ${ }^{1,3}$

\begin{abstract}
Treatment guidelines for osteoarthritis have stressed the need for research on clinical predictors of response to different treatments. However, identifying such clinical predictors of response is less easy than it seems, and there is not a given classification of osteoarthritis subpopulations. This review article highlights the key methodical issues when analyzing and designing clinical studies to detect important subgroups with respect to treatment effect. In addition, we discuss the main osteoarthritis subpopulations and give examples of how specific treatment effects in these subpopulations have been assessed.
\end{abstract}

\section{Introduction}

So far, the effectiveness of symptomatic-based treatments for osteoarthritis (OA) is only small to moderate [1]. Efforts to develop disease-modifying drugs have not yet succeeded in diminishing symptomatic OA [2]. Given the wide range of available treatments in $\mathrm{OA}$ and their small to moderate effectiveness, better-targeted treatment is desirable.

Treatment guidelines for OA have stressed the need for research on clinical predictors of response to different treatments [3,4]. For example, the OA guideline of the Royal College of Physicians specifically mentions the complexity of $\mathrm{OA}$ in terms of pain and range of structural pathology, that few useful subclassifications of OA exist with respect to targeted treatment, and that it is unclear in which way co-morbidity in patients with OA influences treatment outcome [4].

Rothwell [5] identified several situations where a search for clinically important heterogeneity of treatment effects should be considered: first, in case multiple pathologies

*Correspondence: s.bierma-zeinstra@erasmusmc.nl

'Department of General Practice, University Medical Centre Erasmus MC, 3000 CA Rotterdam, The Netherlands

Full list of author information is available at the end of the article underlie a clinical syndrome; and second, in diseases with different severity and/or at different stages, or where comorbidity is frequently present. Both situations apply to OA patients; however, there is hardly any agreement about the classification of such OA subgroups.

Moreover, identifying clinical predictors of response to treatment is not simple. It is essential to use the correct methodology to identify such subgroups in order to avoid that some patients are erroneously deprived of certain treatments, or are erroneously assumed to have an (better) effect from such treatment. Therefore, this overview will discuss methodology of identifying clinical predictors of response to different treatments, and propose the main OA subpopulations and give examples of how specific treatment effects in these subpopulations have been assessed.

\section{Methods}

This overview is based on a pragmatic search of the literature. In order to discuss the methodology, we searched in the Medline library for articles on the subject 'subgroup analysis' in combination with 'treatment' and 'methodology'; a short overview of the main methods found and their implications are discussed, and summarized in Table 1.

In order to give a classification of OA subpopulations, we searched the Medline library for articles on the combination of 'osteoarthritis' and [phenotyp* OR subgroup* OR subpopulation] and [treatment* OR therapy OR intervention*]. Subgroups mentioned in the abstracts were classified under the subheadings phenotypes, structural and symptomatic stage, co-morbidity, and patient characteristics. Finally, we searched for more detailed information on these (kind of) subpopulations and for examples of subgroup analysis with respect to treatment effects. Atrophic hip OA and genotypes were not found but are added, and briefly discussed. The main categories are summarized in Table 2.

\section{Methodology in testing for subgroup effects of treatment}

Subgroup-specific trials are obvious for the different OA joint groups, and for treatment specifically aimed at 
Prognostic factors are not necessarily treatment effect modifiers

Post hoc subgroup effects in trials should be regarded as unreliable unless they can be replicated in dedicated trials or meta-analyses

When subgroup analysis is predefined in a trial, randomisation should be stratified by subgroup and the power should be adjusted to the smallest subgroup

Testing for interaction effects in trials is more robust than subgroup analysis, but needs a well-powered study depending on the expected size of the interaction effect

The number of subgroups should be limited to a minimum to avoid multiple testing

Combining trials for meta-analysis has the potential to search for subgroup effects. For reliable subgroup meta-analysis, individual trials have to supply subgroup effects and use stratified treatment randomization by subgroup, or supply the distribution of prognostic variables over the treatment arms in the subgroup

Meta-analysis using individual patient data is a powerful method and the gold standard for assessing subgroup-treatment interaction effects

\begin{tabular}{l} 
Table 2 . Suggested main subgroups of OA in clinical \\
research \\
\hline OA phenotypes \\
Joint site/joint compartment \\
Localized or generalized osteoarthritis \\
Structural osteoarthritis subtypes \\
Pain phenotypes \\
Structural or symptomatic stage \\
Pain severity \\
Restricted motion \\
Radiographic severity \\
Effusion/synovitis \\
Bone marrow lesions \\
Co-morbidity \\
Obesity \\
Cardiovascular disease \\
Chronic obstructive pulmonary disease \\
Depression \\
Personal factors \\
Gender \\
Age \\
Treatment preference \\
Psychosocial factors \\
\hline
\end{tabular}

certain OA subgroups, such as osteotomy for unicompartment malaligned knee OA. However, to design such trials for every suspected subgroup for the available treatments would take many years of research, and resources. Therefore, subgroup analyses or treatment response analyses within trials are undertaken.

\section{Prognostic factors}

A first issue to be addressed in subgroup analysis is the difference between the subgroup factor as a prognostic factor and as an effect modifier of treatment response. Single arm trials (or assessing predictors of response in only the active treatment group) identify prognostic factors and might wrongly suggest that the effect of treatment is greater in certain subgroups than in others [6]. To be identified as a subgroup that shows a different effect of treatment compared with another subgroup, the subgroup factor should be identified as an effect modifier. This means that the treatment interacts with the subgroup factor with respect to treatment outcome, showing another difference in outcome (effect) between treatment $\mathrm{A}$ and $\mathrm{B}$ in the specific subgroup. Consequently, for such analyses a control group is needed.

\section{Post hoc testing versus predefined testing}

A frequently used method to identify subgroups with respect to effect of treatment is a post hoc analysis. The main analyses for effect of treatment in a two-arm trial are repeated in certain subgroups and tested for significance of effect. However, this kind of analysis includes a high risk of false results; type I as well as type II errors $[7,8]$. Post hoc tests should therefore be regarded as unreliable unless they can be replicated [5].

As outlined by the CONSORT statement, reporting on subgroup effects in trials should only be done when the subgroup to be tested is predefined in the protocol, and the number of subgroups to be tested should be limited to the absolute minimum. The subgroups should be based on previous explorative research or on theoretical considerations, and the direction of the effects should be stated [5]. To anticipate equal distribution of the main prognostic variables over the treatment arms in the subgroups, stratification of randomisation by the subgroup factor is advisable. In a predefined trial with subgroup testing the trial should be powered such that the expected effect, if present, should be detected in the smallest subgroup.

\section{Subgroup-treatment interaction effect}

A methodologically robust method is to test for a subgrouptreatment interaction effect. Such analyses assess the statistical significance of the difference in effect between subgroups [7] by simply testing for a difference in treatment effects making use of a standard normal approximation, or by including interaction terms in a regression model. Assessing interaction carries a much smaller risk of false-positive results. This kind of analysis will only show a positive result for interaction when the subgrouptreatment interaction is very strong, or when the trial is 
powered to show such a result. In a trial specifically designed to detect the supposed subgroup-treatment interactions, the sample size should be inflated fourfold when the interaction effect is equal to the overall treatment effect. When the interaction effect is only half of the overall treatment effect, the inflation factor is already 16 [8].

\section{Meta-analysis of randomised controlled trials}

A solution might be found in meta-analyses. Metaregression, one of the methods used, aims to relate the treatment effect recorded in the different trials to the characteristics of those trials in which the study is the unit of analysis. Even if appropriate statistical methods are used, relations with averages of the patients' characteristics in the trials are potentially misleading [9], due to confounding, unequal distributions, or to lack of power. Another method, meta-analysis dedicated to certain subgroups, might be possible when subgroup effects are reported, or when data on the subgroup effects can be retrieved from the authors. For a valid interpretation of these results, a stratified randomisation by subgroup factor in the individual trials is needed, or information on the distribution of prognostic variables over the treatment arms in the subgroup should be supplied.

\section{Meta-analysis with individual patient data}

The third method, a meta-analysis for quantifying interaction effects using individual patient data (IPD), might overcome the power problem in individual trials and meta-regression analysis. A meta-analysis in which reanalysis of all IPD can be accomplished is widely considered to be the gold standard. Authors of the included trials can be requested to make available their IPD, and/or well-designed collaborative projects can be initiated. In a meta-analysis using IPD, in which the data of several trials are pooled, the interaction effects between subgroups and treatment can be reliably assessed and potential confounders can be adjusted for [10]. Essential for such an analysis is that the baseline data with respect to defining subgroups and confounders are obtained in similar ways

\section{Osteoarthritis subpopulations \\ Phenotypes}

The historical classification of $\mathrm{OA}$ in primary and secondary OA has been abandoned because OA is always secondary to something, and usually to a combination of factors [11]. Still, a way to define distinct phenotypes of OA could be based on the main risk factors and etiological factors [12]. Phenotypes can also be based on structural appearances, localization, site of manifestation, and on pain types.

\section{Joint site}

The different joint groups are generally seen as distinct phenotypes. For example, knee, hand, hip, and spine OA have different risk factors [13-15], and inheritance factors might be linked to joint-specific genes [16]. Even within these localizations there are distinct differences between, for example, localized thumb OA and nodal interphalangeal hand OA $[17,18]$, and between patellofemoral OA only and multi-compartment knee OA $[19,20]$. In addition, the different joint sites can have different structural and symptomatic appearances [21]. In spinal OA, specific neurological symptoms like neurogenic claudication, numbness, tingling, or weakness can be present due to lumbar spinal stenosis [22]. Whether or not treatment effects are expected to differ between these specific joint sites might depend on the kind of treatment.

\section{Examples}

The inflammatory component [21] or type of pain [23] might differ between hip OA and knee OA. Indeed, one study reported a higher effectiveness of oral nonsteroidal anti-inflammatory drugs (NSAIDs) in knee than in hip OA based on a re-analysis of a large trial comparing NSAIDs to placebo in patients with hip or knee OA [24]. However, the authors compared the before and after effects in the NSAID group between hip and knee patients, and not the in-between effects of NSAIDs versus placebo between hip and knee patients. If the placebo effect is also stronger in knee OA patients, there may not be greater effectiveness of NSAIDs in knee OA. In two meta-analyses combining two and three studies, respectively, the difference in the effect of NSAIDs versus placebo between hip and knee OA was formally evaluated for interaction effects in a meta-analysis with IPD. The authors could not show better effectiveness of NSAIDs in knee OA patients than in hip OA patients $[25,26]$. However, the selected studies in these two metaanalyses included patients with increased pain following a wash-out period after NSAIDs (known as the flare design); in this way only potential responders were included and a difference in effect may no longer be expected.

It was not known whether the positive effects of exercise for knee OA could be extrapolated to hip OA because exercise trials mostly included knee OA patients. In the trials combining knee and hip OA, the subgroups with hip OA were often too small for reliable subgroup analysis. Recently, Hernandez-Molina and colleagues [27] retrieved data from subgroups with hip OA in exercise trials that included both patients with hip OA and those with knee OA. With this meta-analysis in a site-specific subgroup the authors could confirm the effectiveness of exercise therapy in hip OA.

\section{Generalized versus local osteoarthritis}

The concept of generalized OA has been widely accepted [12]. Meta-analysis of genome-wide association studies confirmed that at least one allele is linked to a more systemic initiation of OA [28,29]. More rare forms of 
early onset familial and progressive generalized OA have been linked to specific mutations [30]. Systemic acting treatments might be more efficacious in a joint that is part of a generalized OA than in a joint-specific local OA where biomechanical factors may largely contribute to the disease. In addition, a systematic review showed that knee OA as part of generalized OA showed faster progression than local knee OA [31]. Many different definitions for generalized OA have been used. Based on formal cluster analysis in more than a thousand OA patients, Dougados and colleagues [32] suggested that generalized OA should be defined as the presence of bilateral involvement of the fingers, or involvement of spine and both tibiofemoral joints. However, so far there is no agreed definition for generalized OA.

\section{Examples}

Rozendaal and colleagues [33] defined beforehand a subgroup analysis in patients with OA at more joint sites than the hip alone, in a trial assessing the effectiveness of glucosamine sulphate in patients with hip OA. The trial was also powered to assess symptomatic effects in the subgroups, and used a stratified treatment randomization for the subgroup generalized OA. The authors did not show any effect in this subgroup, but the effect was also absent in the total group.

\section{Structural osteoarthritis subtypes}

Whether or not atrophic versus hypertrophic OA, erosive versus non-erosive, and concurrent chondrocalcinosis should be seen as distinct etiological phenotypes or as a continuum of severity, or as being influenced by existing co-factors, is not yet entirely clear.

\section{Atrophic osteoarthritis}

OA can be classified as hypertrophic or atrophic according to the presence or absence of osteophytes. A systematic review showed strong evidence that the atrophic form demonstrates a faster progression of joint space narrowing than in hypertrophic OA [34]. Conrozier and colleagues [35] suggested that atrophic hip OA might be due to a relative deficiency in the synthesis of type II collagen, which is needed for enchondral ossification in the formation of osteophytes.

\section{Erosive osteoarthritis}

Erosive OA appears to be a specific subgroup of hand OA with worse clinical and structural outcomes. The ESCISIT task force [36] postulated that erosive hand OA targets interphalangial joints in the hand and shows radiographic subchondral erosion, which may progress to marked bone and cartilage attrition, instability and bony ankylosis. This kind of hand OA should possibly be treated differently because of the major inflammatory component in erosive hand OA. However, to date, only a few small pilot studies have specifically targeted erosive hand OA [37].

\section{Chondrocalcinosis}

Large calcium-containing crystal deposits in the joint can be detected radiographically and is called chondrocalcinosis (CC). This is seen in 19\% of endstage knee OA, and in 10\% of end-stage hip OA [38]. There is some evidence that these calcium pyrophosphate crystals are biologically active particles that develop in the setting of cartilage damage, but also contribute to the osteoarthritis process [39]. Some studies suggest that OA with $\mathrm{CC}$ may differ from $\mathrm{OA}$ without $\mathrm{CC}$ in showing more osteophytosis and more inflammatory features [40], but whether or not the presence of $\mathrm{CC}$ might interact with various forms of treatment is not yet known. A recent study showed that $\mathrm{CC}$ is not associated with worsening of OA as defined by the progression on MRI [41].

\section{Biomechanical deviations}

Biomechanical deviations in the joint are known to be a risk factor for OA. A detrimental biomechanical influence in mal-aligned varus knees, due to the increased adduction moment in the knee, is widely recognized with respect to both initiation and progression of OA $[42,43]$. Femoral head abnormalities (for example, slipped femoral capital epiphysis) are well-known risk factors for hip OA [44]. Major dysplasia of the hip results in early onset of hip OA with fast progression; however, minor dysplasia is also a risk factor for hip OA [45], and hip OA with supero-lateral migration of the femoral head shows faster progression [34].

Kinematics in a joint might also undergo unfavourable change due to joint laxity and neuromuscular deficiencies. Overall, mechanical abnormalities in a joint are important risk factors for OA, but mechanical abnormalities may also worsen (or be the result of) an osteoarthritic process and become an important prognostic factor.

\section{Injured joints}

Local joint injury, and especially meniscal injury or meniscal ectomy, is widely recognized as being associated with the development of knee OA [46]. Apart from mechanical change in the knee due to these lesions, it is suggested that the biology in the knee has already changed in the first weeks after the acute injury; inflammatory processes in the initial phase are suggested to induce proteoglycan loss followed by subsequent collagen loss [47]. Both pathways might be involved in the initiation of post-traumatic OA with implications for possible preventive treatments. 
Examples

Lim and colleagues [48] performed a trial in which they included both mal-aligned and neutral positioned knee OA patients to assess the effect of quadriceps-strengthening exercises versus control treatment. Based on previous research, due to an increase of quadriceps strength they expected progression of the adduction moment in the mal-aligned group. They powered the trial on interaction between treatment and mal-alignment, but on formal testing found no such interaction effect between treatment and mal-alignment with respect to their primary outcome (adduction moment). However, they did find such an effect with repeated testing in one of the other five outcomes, indicating less pain relief of exercises in mal-aligned knees than in neutral knees. Given the reported significance for the interaction effect $(P<$ 0.001), the subgroup with varus alignment seems to need another kind of (exercise) treatment.

\section{Pain phenotypes}

Pain in OA differs between and within patients. At present there are more or less consistent reports on an association between OA pain and the presence of joint effusion, or subchondral bone lesions [49]. Other suggested causes of pain in OA are bone attrition [50], neurovascular invasion at the osteochondral junction [51], and ligament and tendon pathology [52]. How and whether these different sources of pain are reflected in different pain phenotypes is not well known. Night pain, pain at rest, and pain under load are the usual pain phenotypes mentioned in OA. In qualitative research, Hawker and colleagues [23] identified two main types of pain in people with OA of the knee and hip; a fairly constant (not disturbing) background pain, and a less frequent but more intense and often unpredictable pain.

In addition, different pain mechanisms in OA can exist. Besides the nociceptive pain, neuropathic pain might develop, for which different screenings tools are available [53]. Central sensitization can also be present in chronic pain. Although the traditional assessment of central sensitization is complex, Nijs and colleagues [54] proposed a more simple assessment to be used in clinical practice. These different pain phenotypes in OA can be of importance to target pain treatment, but at present very little OA intervention research in this direction has been done.

\section{Genotypes}

\section{Osteoarthritis genotypes}

So far, genotyping of OA has aimed to identify pathways in OA and find new targets for treatment. However, in future studies, combinations of genetic markers might also predict the risk for OA and identify certain subgroups with an increased risk for OA, identify subgroups of OA patients with fast progression, or identify OA patients susceptible for aseptic loosening of a prosthesis [55]. As yet, OA genotyping has not found any such clinical application.

\section{Pain genotypes}

A topic of increasing interest in recent OA research is the genetic variation in oa patients with respect to sensitivity for pain; a variation that might indicate a different need of pain management. One example is the catechol-Omethyltransferase polymorphism in which the sensitivity for pain is increased [56,57]. Also, increasing data are available regarding several polymorphisms that influence the analgesic efficacy of nsaids, tramadol, codeine, and tryglyceric antidepressants, all with respect to drug metabolism [58]. More research in this area is needed, but will probably focus on pain syndromes in general rather than specifically on OA pain.

\section{Structural or symptomatic stage of osteoarthritis}

Knowing that OA is a progressive disease, it is important to establish at what stage of the disease certain treatment will be most effective. For example, for intended diseasemodifying drugs it is not expected that these will have any effect in a stage with pronounced structural changes or where apparent deleterious mechanical components are present [11].

Treatment effect might also depend on the severity of disease and specific symptoms. For example, the severity of pain, muscle weakness, restricted range of motion, and the presence or not of intra-articular joint effusion or synovitis in combination with a symptomatic flare might all influence the effects of different doses or types of pain medication, anti-inflammatory treatment, and exercise treatment or manual therapy.

Subchondral bone marrow lesions, an MRI sign that is seen in some OA patients and that can also disappear over time, represent foci of fibrosis and of osteonecrosis and bone remodelling [59]. Some of these are microfractures of the trabecular bone at different stages of healing. These bone marrow lesions have been shown to correlate with the severity of pain and with progression of the disease [60]. Therefore, people with and without these signs might respond differently to certain treatment modalities.

\section{Examples}

Pincus and colleagues [61] evaluated the comparative pain reduction of NSAIDs and acetaminophen in patients with hip or knee OA, and assessed the interaction between type of medication and a pooled severity score, based on radiographic severity, symptomatic severity, and number of involved joints. Significant interaction effects were reported (without showing details), indicating similar effectiveness in the mildest group, but superior 
effectiveness of NSAIDs in the more severe groups. The same was found when assessing the separate indicators for severity, except for the radiographic ones.

In clinical practice intra-articular corticosteroid injections are indicated in patients with knee effusion. However, there is limited evidence that such treatment might provide better effectiveness in those with effusions. Gaffney and colleagues [62] showed significantly better effect in the subgroup with clinical signs of effusion than in the subgroup without effusion. Another study showed no indication for better effects in the subgroup with signs of effusion [63], and a third study even found better results in the non-effusion group [64]. All studies assessed this effect only in the active treatment group and, therefore, only identified prognostic factors and not necessarily predictors of differences in effect.

\section{Co-morbidity}

Major well-known co-morbidities in OA patients are cardiovascular disease, obesity, and diabetes. However, sensory impairments, chronic obstructive pulmonary disease, and chronic low back pain are also frequent comorbidities in OA patients [65]. These diseases, their associated disabilities and/or medication may all interact with treatment for OA. For example, cardiovascular riskprofile, renal function, glycaemic index history, and the use of anti-platelets or anti-hypertensive drugs will all influence the choice of whether to treat or not with a NSAID and what type to use [66]. Musculoskeletal comorbidity has repeatedly been shown to influence severity of symptoms $[65,67,68]$; coexistent lower back pain has also been shown to predict future pain and disability in people with hip OA [69]. The presence of coexistent lower back pain or buttock pain, often in combination with spine $\mathrm{OA}$, is also a possible reason for continued pain at that location after total hip arthroplasty and dissatisfaction with the surgery [70].

Concurrent depressive complaints are frequently seen in OA patients [71] and may also interfere with treatment or treatment compliance. However, the ways in which comorbid conditions in people with OA influence outcomes of treatment have hardly been explored [4].

A high body mass index is a well-known risk factor for knee OA, and to a lesser degree for hip OA and hand OA, and probably acts through a change in load distribution in the knee [72], and systemic and local inflammatory cytokines $[73,74]$ released by the adipose tissue. It also seems, however, to influence severity of symptoms; overweight people more often experience morning stiffness in the knee and have more severe knee pain than those who are not overweight but with the same degree of radiographic severity [75]. Although weight loss is a main goal in overweight OA patients, their weight might also have implications for other OA treatments.

\section{Patient characteristics}

Gender, age, educational level, and psychosocial characteristics might all influence the effect of treatment. Above the age of 50 years, the incidence of OA rises steeply in women but less so in men, suggesting an association with changes in female hormone levels during menopause. However, systematic reviews could not find clear evidence for the assumed association between OA and aspects concerning the fertile period and menopause; only some evidence of a protective effect of unopposed oestrogen use for hip OA was found [76,77]. Recently, it was found that symptomatic postmenopausal women clearly differ from those without vasomotor symptoms with respect to the risk for future cardiovascular disease [78]. This might also be the case with respect to OA. Whether or how female hormone levels or other female characteristics interact with different kinds of treatment is not yet known.

Depending on the type of intervention, one might consider the interaction of such characteristics with the treatment. For example, treatments that include a change of lifestyle, or behavioural treatment, might be highly dependent on intrinsic motivation, or on psychological factors, like coping style or level of locus of internal control [79]. Another well-known factor that influences treatment effect is the expectation the patient has about the treatment. A systematic review found that, in randomised open-label trials (back pain trials), about $57 \%$ of patients had a treatment preference, and that the effect size increased by 0.162 in patients with a treatment preference that also received this treatment compared to the 'indifferent' patients [80].

\section{Examples}

Veenhof and colleagues [81] assessed which hip or knee OA patients benefit most from a specific treatment in a randomised controlled trial on behavioural graded activity therapy versus common exercise therapy. They tested for interaction effects in a multivariable model and found that patients with a relatively low level of physical functioning benefit more from behavioural therapy than from common exercise therapy. For a low level of internal locus of control the interaction with the kind of treatment was marginally significant.

\section{Conclusions}

Defining subgroups in OA remains difficult, especially because the etiopathogenesis of OA is not yet fully understood. It becomes even more complicated when the mechanism of action in treatments is not fully elucidated. In addition, several subgroups may well be derived from different dimensions of the disease and be treatment specific and will, therefore, overlap each other. Because of this, a mutually exclusive classification of subgroups with 
respect to targeted treatment may not only be impossible to achieve, but may also not be desirable.

In addition, when defining subgroups in clinical research, one should keep in mind that the ultimate goal of identifying a subgroup that is responsive to a specific treatment is that clinicians can also identify these patients in practice. Should subgrouping become more costly, invasive or time consuming than the treatment itself, it will not be clinically applicable and may have only helped us to understand the mechanism of action of a specific type of treatment.

Because OA is a heterogeneous disease, identifying subgroups for treatments is probably one of the promising ways forward in clinical research. This can only be achieved when the correct methodology to identify such subgroups is used, and the frequently reported post hoc testing is only regarded as hypothesis generating.

International collaborative initiatives aiming to define the most promising treatment-specific subgroups are needed and consensus should be reached on the case definition of these subgroups. Such subgroup definitions can be used for predefined subgroup analysis or dedicated trials, or for equal baseline measurement of these subgroup factors in trials to facilitate future metaanalyses, as well as initiatives to combine IPD from several randomised controlled trials, all in order to generate appropriate recommendations for the effective treatment of various subgroups.

This article is part of a review series on New developments in osteoarthritis, edited by Martin Lotz and Stfan Lohmander. Other articles in the series can be found online at http://arthritis-research.com/series/osteoarthritis

\section{Abbreviations}

CC, chondrocalcinosis; IPD, individual patient data; MRI, magnetic resonance imaging; NSAID, nonsteroidal anti-inflammatory drug; OA, osteoarthritis.

\section{Competing interests}

The authors declare that they have no competing interests.

\section{Author details}

'Department of General Practice, University Medical Centre Erasmus MC, 3000 CA Rotterdam, The Netherlands. . 2 Department of Orthopedics, University Medical Centre Erasmus MC, 3000 CA Rotterdam, The Netherlands. ${ }^{3}$ Avans University of Applied Sciences, School of Health, 4800 RA Breda, The Netherlands.

\section{Published: 5 April 2011}

\section{References}

1. Zhang W, Moskowitz RW, Nuki G, Abramson S, Altman RD, Arden N, BiermaZeinstra S, Brandt KD, Croft P, Doherty M, Dougados M, Hochberg M, Hunter DJ, Kwoh K, Lohmander LS, Tugwell P: OARSI recommendations for the management of hip and knee osteoarthritis, Part II: OARSI evidencebased, expert consensus guidelines. Osteoarthritis Cartilage 2008, 16:137-162.

2. Hunter DJ, Hellio Le Graverand-Gastineau MP: How close are we to having structure-modifying drugs available? Med Clin North Am 2009, 93:223-234.

3. Zhang W, Doherty M, Arden N, Bannwarth B, Bijlsma J, Gunther KP,
Hauselmann HJ, Herrero-Beaumont G, Jordan K, Kaklamanis P, Leeb B, Lequesne M, Lohmander S, Mazieres B, Martin-Mola E, Pavelka K, Pendleton A, Punzi L, Swoboda B, Varatojo R, Verbruggen G, Zimmermann-Gorska I, Dougados M; EULAR Standing Committee for International Clinical Studies Including Therapeutics (ESCISIT): EULAR evidence based recommendations for the management of hip osteoarthritis: report of a task force of the EULAR Standing Committee for International Clinical Studies Including Therapeutics (ESCISIT). Ann Rheum Dis 2005, 64:669-681.

4. National Collaborating Centre for Chronic Conditions: Osteoarthritis: national clinical guideline for care and management in adults. London: Royal College of Physicians (UK); 2008.

5. Rothwell PM: External validity of randomised controlled trials: "to whom do the results of this trial apply?". Lancet 2005, 365:82-93.

6. Hancock M, Herbert RD, Maher CG: A guide to interpretation of studies investigating subgroups of responders to physical therapy interventions. Phys Ther 2009, 89:698-704.

7. Brookes ST, Whitley E, Peters TJ, Mulheran PA, Egger M, Davey Smith G: Subgroup analyses in randomised controlled trials: quantifying the risks of false-positives and false-negatives. Health Technol Assess 2001, 5:1-56.

8. Brookes ST, Whitely E, Egger M, Smith GD, Mulheran PA, Peters TJ: Subgroup analyses in randomized trials: risks of subgroup-specific analyses; power and sample size for the interaction test. J Clin Epidemio/ 2004, 57:229-236.

9. Sharp SJ, Thompson SG: Analysing the relationship between treatment effect and underlying risk in meta-analysis: comparison and development of approaches. Stat Med 2000, 19:3251-3274

10. Groenwold RH, Donders AR, van der Heijden GJ, Hoes AW, Rovers MM: Confounding of subgroup analyses in randomized data. Arch Intern Med 2009, 169:1532-1534.

11. Brandt KD, Dieppe P, Radin E: Etiopathogenesis of osteoarthritis. Med Clin North Am 2009, 93:1-24.

12. Felson DT: Identifying different osteoarthritis phenotypes through epidemiology. Osteoarthritis Cartilage 2010, 18:601-604.

13. Reijman M, Pols HA, Bergink AP, Hazes JM, Belo JN, Lievense AM, BiermaZeinstra SM: Body mass index associated with onset and progression of osteoarthritis of the knee but not of the hip: the Rotterdam Study. Ann Rheum Dis 2007, 66:158-162.

14. Dahaghin S, Bierma-Zeinstra SM, Reijman M, Pols HA, Hazes JM, Koes BW: Does hand osteoarthritis predict future hip or knee osteoarthritis? Arthritis Rheum 2005, 52:3520-3527.

15. Kalichman L, Guermazi A, Li L, Hunter DJ: Association between age, sex, BMI and CT-evaluated spinal degeneration features. J Back Musculoskelet Rehabil 2009, 22:189-195.

16. Evangelou E, Chapman K, Meulenbelt I, Karassa FB, Loughlin J, Carr A, Doherty M, Doherty S, Gómez-Reino JJ, Gonzalez A, Halldorsson BV, Hauksson VB, Hofman A, Hart DJ, Ikegawa S, Ingvarsson T, Jiang Q, Jonsdottir I, Jonsson H, Kerkhof HJ, Kloppenburg M, Lane NE, Li J, Lories RJ, van Meurs JB, Näkki A, Nevitt MC, Rodriguez-Lopez J, Shi D, Slagboom PE, et al: Large-scale analysis of association between GDF5 and FRZB variants and osteoarthritis of the hip, knee, and hand. Arthritis Rheum 2009, 60:1710-1721.

17. Jónsson H, Valtýsdóttir ST, Kjartansson O, Brekkan A: Hypermobility associated with osteoarthritis of the thumb base: a clinical and radiological subset of hand osteoarthritis. Ann Rheum Dis 1996, 55:540-543.

18. Irlenbusch U, Schäller T: Investigations in generalized osteoarthritis. Part 1: genetic study of Heberden's nodes. Osteoarthritis Cartilage 2006, 14:423-427.

19. Duncan R, Peat G, Thomas E, Wood L, Hay E, Croft P: Does isolated patellofemoral osteoarthritis matter? Osteoarthritis Cartilage 2009, 17:1151-1155

20. Hunter DJ, March L, Sambrook PN: The association of cartilage volume with knee pain. Osteoarthritis Cartilage 2003, 11:725-729.

21. Meulenbelt I, Kloppenburg M, Kroon HM, Houwing-Duistermaat JJ, Garnero P, Hellio-Le Graverand MP, DeGroot J, Slagboom PE: Clusters of biochemical markers are associated with radiographic subtypes of osteoarthritis (OA) in subject with familial OA at multiple sites. The GARP study. Osteoarthritis Cartilage 2007, 15:379-385.

22. De Graaf IC, Prak A, Bierma-Zeinstra SMA, Thomas S, Peul WC, Koes BW: Diagnosis of lumbar spinal stenosis: a systematic review of the accuracy of diagnostic tests. Spine 2006, 31:1168-1176.

23. Hawker GA, Stewart L, French MR, Cibere J, Jordan JM, March L, SuarezAlmazor M, Gooberman-Hill R: Understanding the pain experience in hip and knee osteoarthritis - an OARSI/OMERACT initiative. Osteoarthritis 
Cartilage 2008, 16:415-422.

24. Svensson O, Malmenäs M, Fajutrao L, Roos EM, Lohmander LS: Greater reduction of knee than hip pain in osteoarthritis treated with naproxen, as evaluated by WOMAC and SF-36. Ann Rheum Dis 2006, 65:781-784.

25. Bingham CO 3rd, Sebba Al, Rubin BR, Ruoff GE, Kremer J, Bird S, Smugar SS, Fitzgerald BJ, O'Brien K, Tershakovec AM: Efficacy and safety of etoricoxib $30 \mathrm{mg}$ and celecoxib $200 \mathrm{mg}$ in the treatment of osteoarthritis in two identically designed, randomized, placebo-controlled, non-inferiority studies. Rheumatology (Oxford) 2007, 46:496-507.

26. Detora LM, Krupa D, Bolognese J, Sperling RS, Ehrich EW: Rofecoxib shows consistent efficacy in osteoarthritis clinical trials, regardless of specific patient demographic and disease factors. J Rheumatol 2001, 28:2494-2503.

27. Hernández-Molina G, Reichenbach S, Zhang B, Lavalley M, Felson DT: Effect of therapeutic exercise for hip osteoarthritis pain: results of a metaanalysis. Arthritis Rheum 2008, 59:1221-1228.

28. Miyamoto Y, Mabuchi A, Shi D, Kubo T, Takatori Y, Saito S, Fujioka M, Sudo A, Uchida A, Yamamoto S, Ozaki K, Takigawa M, Tanaka T, Nakamura Y, Jiang Q, Ikegawa S: A functional polymorphism in the 5' UTR of GDF5 is associated with susceptibility to osteoarthritis. Nat Genet 2007, 39:529-533.

29. MacGregor A, Li Q, Spector TD, Williams FMK: The genetic influence on radiographic osteoarthritis is site specific at the hand, hip and knee. Rheumatology (Oxford) 2009, 48:277-280

30. Min JL, Meulenbelt I, Kloppenburg M, van Duijn CM, Slagboom PE: Mutation analysis of candidate genes within the 2q33.3 linkage area for familial early-onset generalised osteoarthritis. Eur J Hum Genet 2007, 15:791-799.

31. Belo JN, Berger MY, Reijman M, Koes BW, Bierma-Zeinstra SMA: Prognostic factors of progression of osteoarthritis of the knee - a systematic review of observational studies. Arthritis Rheum 2007, 57:13-26.

32. Dougados M, Nakache JP, Gueguen A: Criteria for generalized and focal osteoarthritis. Rev Rhum Engl Ed 1996, 63:569-575.

33. Rozendaal RM, Uitterlinden EJ, van Osch GJ, Garling EH, Willemsen SP, Ginai AZ, Verhaar JA, Weinans H, Koes BW, Bierma-Zeinstra SM: Effect of glucosamine sulphate on joint space narrowing, pain and function in patients with hip osteoarthritis; subgroup analyses of a randomized controlled trial. Osteoarthritis Cartilage 2009, 17:427-432.

34. Lievense AM, Bierma-Zeinstra SM, Verhagen AP, Verhaar JA, Koes BW: Prognostic factors of progress of hip osteoarthritis: a systematic review. Arthritis Rheum 2002, 47:556-562.

35. Conrozier T, Ferrand F, Poole AR, Verret C, Mathieu P, Ionescu M, Vincent F, Piperno M, Spiegel A, Vignon E: Differences in biomarkers of type Il collagen in atrophic and hypertrophic osteoarthritis of the hip: implications for the differing pathobiologies. Osteoarthritis Cartilage 2007, 15:462-467.

36. Zhang W, Doherty M, Leeb BF, Alekseeva L, Arden NK, Bijlsma JW, Dincer F, Dziedzic K, Hauselmann HJ, Kaklamanis P, Kloppenburg M, Lohmander LS, Maheu E, Martin-Mola E, Pavelka K, Punzi L, Reiter S, Smolen J, Verbruggen G, Watt I, Zimmermann-Gorska I: ESCISIT: EULAR evidence-based recommendations for the diagnosis of hand osteoarthritis: report of a task force of ESCISIT. Ann Rheum Dis 2009, 68:8-17.

37. Punzi L, Frigato M, Frallonardo P, Ramonda R: Inflammatory osteoarthritis of the hand. Best Pract Res Clin Rheumatol 2010, 24:301-312.

38. Abhishek A, Doherty M: Pathophysiology of articular chondrocalcinosisrole of ANKH. Nat Rev Rheumatol 2011, 7:96-104.

39. Rosenthal AK: Calcium crystal deposition and osteoarthritis. Rheum Dis Clin North Am 2006, 32:401-412.

40. Zhang W, Doherty M, Bardin T, Barskova V, Guerne PA, Jansen TL, Leeb BF, Perez-Ruiz F, Pimentao J, Punzi L, Richette P, Sivera F, Uhlig T, Watt I, Pascual E: European League Against Rheumatism recommendations for calcium pyrophosphate deposition. Part I: terminology and diagnosis. Ann Rheum Dis 2011, 70:563-570

41. Neogi T, Nevitt M, Niu J, LaValley MP, Hunter DJ, Terkeltaub R, Carbone L, Chen $H$, Harris T, Kwoh K, Guermazi A, Felson DT: Lack of association between chondrocalcinosis and increased risk of cartilage loss in knees with osteoarthritis: results of two prospective longitudinal magnetic resonance imaging studies. Arthritis Rheum 2006, 54:1822-1828.

42. Sharma L, Song J, Dunlop D, Felson D, Lewis CE, Segal N, Torner J, Cooke TD, Hietpas J, Lynch J, Nevitt M: Varus and valgus alignment and incident and progressive knee osteoarthritis. Ann Rheum Dis 2010, 69:1940-1945.

43. Brouwer GM, van Tol AW, Bergink AP, Belo JN, Bernsen RM, Reijman M, Pols HA, Bierma-Zeinstra SM: Association between valgus and varus alignment and the development and progression of radiographic osteoarthritis of the knee. Arthritis Rheum 2007, 56:1204-1211.
44. Carney BT, Weinstein SL, Noble J: Long-term follow-up of slipped capital femoral epiphysis. J Bone Joint Surg Am 1991, 73:667-674.

45. Reijman M, Hazes JM, Pols HA, Koes BW, Bierma-Zeinstra SM: Acetabular dysplasia predicts incident osteoarthritis of the hip: the Rotterdam study. Arthritis Rheum 2005, 52:787-793.

46. Englund $\mathrm{M}$ : The role of biomechanics in the initiation and progression of OA of the knee. Best Pract Res Clin Rheumatol 2010, 24:39-46.

47. Catterall JB, Stabler TV, Flannery CR, Kraus VB: Changes in serum and synovial fluid biomarkers after acute injury. Arthritis Res Ther 2010, 12:R229.

48. Lim BW, Hinman RS, Wrigley TV, Sharma L, Bennell KL: Does knee malalignment mediate the effects of quadriceps strengthening on knee adduction moment, pain, and function in medial knee osteoarthritis? A randomized controlled trial. Arthritis Rheum 2008, 59:943-951.

49. Felson DT: Developments in the clinical understanding of osteoarthritis. Arthritis Res Ther 2009, 11:203.

50. Hernández-Molina G, Neogi T, Hunter DJ, Niu J, Guermazi A, Roemer FW, McLennan CE, Reichenbach S, Felson DT: The association of bone attrition with knee pain and other MRI features of osteoarthritis. Ann Rheum Dis 2008, 67:43-47.

51. Suri S, Gill SE, Massena de Camin S, Wilson D, McWilliams DF, Walsh DA: Neurovascular invasion at the osteochondral junction and in osteophytes in osteoarthritis. Ann Rheum Dis 2007, 66:1423-1428.

52. Hill CL, Gale DR, Chaisson CE, Skinner K, Kazis L, Gale ME, Felson DT: Periarticular lesions detected on magnetic resonance imaging: prevalence in knees with and without symptoms. Arthritis Rheum 2003, 48:2836-2844.

53. Bennett MI, Attal N, Backonja MM, Baron R, Bouhassira D, Freynhagen R, Scholz J, Tolle TR, Wittchen HU, Jensen TS: Using screening tools to identify neuropathic pain. Pain 2007, 127:199-203.

54. Nijs J, Van Houdenhove B, Oostendorp RA: Recognition of central sensitization in patients with musculoskeletal pain: Application of pain neurophysiology in manual therapy practice. Man Ther 2010, 15:135-141.

55. Valdes AM, Spector TD: The clinical relevance of genetic susceptibility to osteoarthritis. Best Pract Res Clin Rheumatol 2010, 24:3-14.

56. van Meurs JB, Uitterlinden AG, Stolk L, Kerkhof HJ, Hofman A, Pols HA, BiermaZeinstra SM: A functional polymorphism in the catechol-Omethyltransferase gene is associated with osteoarthritis-related pain Arthritis Rheum 2009, 60:628-629.

57. Nackley AG, Diatchenko L: Assessing potential functionality of catechol-Omethyltransferase (COMT) polymorphisms associated with pain sensitivity and temporomandibular joint disorders. Methods Mol Biol 2010, 617:375-393.

58. Stamer UM, Zhang L, Stüber F: Personalized therapy in pain management: where do we stand? Pharmacogenomics 2010, 11:843-864.

59. Zanetti $\mathrm{M}$, Bruder $\mathrm{E}$, Romero J, Hodler J: Bone marrow edema pattern in osteoarthritis knees: correlation between MR imaging and histologic findings. Radiology 2000, 215:835-840.

60. Goldring SR: Role of bone in osteoarthritis pathogenisis. Med Clin North Am 2009, 93:25-35.

61. Pincus T, Koch GG, Sokka T, Lefkowith J, Wolfe F, Jordan JM, Luta G,Callahan LF, Wang X, Schwartz T, Abramson SB, Caldwell JR, Harrell RA, Kremer JM, Lautzenheiser RL, Markenson JA, Schnitzer TJ, Weaver A, Cummins P, Wilson A, Morant S, Fort J: A randomized, double-blind, crossover clinical trial of diclofenac plus misoprostol versus acetaminophen in patients with osteoarthritis of the hip or knee. Arthritis Rheum 2001, 44:1587-1598.

62. Gaffney K, Ledingham J, Perry JD: Intra-articular triamcinolone hexacetonide in knee osteoarthritis: Factors influencing the clinical response. Annals Rheum Dis 1995, 54:379-381.

63. Jones A, Doherty M: Intra-articular corticosteroids are effective in osteoarthritis but there are no clinical predictors of response. Annals Rheum Dis 1996, 55:829-832.

64. Chao J, Wu C, Sun B, Hose MK, Quan A, Hughes TH, Boyle D, Kalunian KC Inflammatory characteristics on ultrasound predict poorer long-term response to intra-articular corticosteroid injections in knee osteoarthritis. J Rheumatol 2010, 37:650-655.

65. Reeuwijk KG, de Rooij M, van Dijk GM, Veenhof C, Steultjens MP, Dekker J: Osteoarthritis of the hip or knee: which coexisting disorders are disabling? Clin Rheumatol 2010, 29:739-747.

66. Tannenbaum H, Bombardier C, Davis P, Russel AS; Third Canadian Consensus Conference Group: An evidence based approach to prescribing nonsteroidal anti-inflammatory drugs. J Rheumatol 2006, 33:140-157.

67. Suri P, Morgenroth DC, Kwoh CK, Bean JF, Kalichman L, Hunter DJ: Low back 
pain and other musculoskeletal pain comorbidities in individuals with symptomatic osteoarthritis of the knee: data from the osteoarthritis initiative. Arthritis Care Res (Hoboken) 2010, 62:1715-1723.

68. Wesseling J, Bierma-Zeinstra SM, Dekker J, Gorter KJ, Roorda LD, Bij|sma JW: Self reported comorbidity and health status in early OA: The CHECK study. Osteoarthritis Cartilage 2010, 18 Suppl 2:S127-S128.

69. Stupar M, Côté P, French MR, Hawker GA: The association between low back pain and osteoarthritis of the hip and knee: a population-based cohort study. J Manipulative Physiol Ther 2010, 33:349-354.

70. Parvizi J, Pour AE, Hillibrand A, Goldberg G, Sharkey PF, Rothman RH: Back pain and total hip arthroplasty: a prospective natural history study. Clin Orthop Relat Res 2010, 468:1325-1330

71. Sale JE, Gignac M, Hawker G: The relationship between disease symptoms, life events, coping and treatment, and depression among older adults with osteoarthritis. J Rheumatol 2008, 35:335-342.

72. Runhaar J, Koes B, Bierma-Zeinstra S: Obesity and biomechanics of everyday movements; a systematic review. Osteoarthritis Cartilage 2009, 17 Suppl 1:S91.

73. Toussirot E, Streit $G$, Wendling D: The contribution of adipose tissue and adipokines to inflammation in joint diseases. Curr Med Chem 2007, 14:1095-1100.

74. Clockaerts S, Bastiaansen-Jenniskens YM, Runhaar J, Van Osch GJ, Van Offel JF, Verhaar JA, De Clerck LS, Somville J: The infrapatellar fat pad should be considered as an active osteoarthritic joint tissue: a narrative review. Osteoarthritis Cartilage 2010, 18:876-882.

75. de Klerk BM, Schiphof D, Koes BW, Bierma-Zeinstra SM: Risk factors and symptomatic symtoms of radiological knee osteoarthritis: Does BMI make a difference? Osteoarthritis Cartilage 2010, 18 Suppl 2:S152-S152.
76. de Klerk BM, Schiphof D, Groeneveld FPMJ, Koes BW, van Osch GJVM, van Meurs JBJ, Bierma-Zeinstra SMA: No clear association between femalehormonal aspects and osteoarthritis of the hand, hip and knee: A systematic review. Rheumatology 2009, 48:1 160-1165.

77. de Klerk BM, Schiphof D, Groeneveld FPMJ, Koes BW, van Osch GJVM, van Meurs JBJ, Bierma-Zeinstra SMA: Limited evidence for a protective effect of unopposed oestrogen therapy for osteoarthritis of the hip. Rheumatology 2009, 48:104-112.

78. Gast GC, Pop VJ, Samsioe GN, Grobbee DE, Nilsson PM, Keyzer JJ, Wijnandsvan Gent CJ, van der Schouw YT: Vasomotor menopausal symptoms are associated with increased risk of coronary heart disease. Menopause 2011, 18:146-151.

79. Keefe FJ, Smith SJ, Buffington AL, Gibson J, Studts JL, Caldwell DS: Recent advances and future directions in the biopsychosocial assessment and treatment of arthritis. J Consult Clin Psychol 2002, 70:640-655.

80. Preference Collaboration Review Group: Patients' preferences within randomised trials: systematic review and patient level meta-analysis. BMJ 2008, 337:a1864

81. Veenhof C, Van den Ende CH, Dekker J, Kiike AJ, Oostendorp RA, Bijlsma JW: Which patients with osteoarthritis of hip and/or knee benefit most from behavioral graded activity? Int J Behav Med 2007, 14:86-91.

doi:10.1186/ar3299

Cite this article as: Bierma-Zeinstra SMA, Verhagen AP: Osteoarthritis subpopulations and implications for clinical trial design. Arthritis Research \& Therapy 2011, 13:213. 